\title{
Characterization of Microseismic Noise in Cape Verde
}

\author{
by Joana F. Carvalho, ${ }^{\star}$ Graça Silveira, ${ }^{\dagger}$ Martin Schimmel, and Eleonore Stutzmann
}

\begin{abstract}
The interaction of ocean waves with either the seafloor or other ocean waves generates primary (PM) and secondary microseisms (SM) that propagate through the crust and mantle, predominantly as Rayleigh waves. The horseshoe geometry and surrounding bathymetry of the Cape Verde archipelago play a significant role in the ambient-noise generation in this region. We analyze the microseisms recorded in the region using two different temporary seismic networks, and we determine the number of signals polarized as Rayleigh waves and their back azimuth (BAZ) as a function of time and frequency. The relative number of polarized signals between PM and $\mathrm{SM}$ varies between the stations. At most of the stations, the SM can be divided into two frequency bands. At lower frequencies $(0.1-0.2 \mathrm{~Hz})$, the number of SM signals is stable throughout the year, whereas at higher frequencies $(0.2-0.3 \mathrm{~Hz})$ this number varies with the season, with more polarized signals during the northern hemisphere spring and summer. In both frequency ranges and at most stations, the BAZ does not vary significantly over the year and points toward sources within the archipelago and outside. We compute the source site effect and show that the local bathymetry around the Cape Verde Islands strongly amplifies local SM sources. Finally, we compare the measured BAZ with source areas derived from an ocean-wave model, which confirms that Cape Verde stations mostly record local sources.
\end{abstract}

\section{Introduction}

The absence of earthquakes or big explosions is no longer a problem in the study of the Earth's interior structure. Ambient seismic noise (ASN) is omnipresent, recorded in a broad frequency band. It can be recorded on multiple orders of magnitude, from a few millihertz to several tens of hertz. It is also clearly visible on seismograms that are recorded by seismic stations worldwide, whatever their location on continents, islands (Stutzmann et al., 2000), or on the ocean floor (e.g., Stutzmann et al., 2001; Corela et al., 2017). The application of ASN when it comes to mapping and to monitoring the Earth's subsurface structure is now widely used. This technique is particularly attractive and inexpensive in areas where the source-receiver geometry and uneven seismicity distribution make it difficult to obtain high-resolution models via traditional passive seismology. Advances in the computational speed and storage made possible the quick analysis of years or even decades of continuous seismic data (Koper and Hawley, 2010; Takagi et al., 2018), extending our knowledge of the crust and upper mantle on multiple scales and in different tectonic environments (e.g., Shapiro and Campillo, 2004; Shapiro et al., 2005; Yang et al.,

\footnotetext{
*Also at Faculdade de Ciências da Universidade de Lisboa, Campo Grande, 1749-016 Lisbon, Portugal.

†Also at Instituto Superior de Engenharia de Lisboa, Rua Rua Conselheiro Emídio Navarro 1, 1959-007 Lisbon, Portugal.
}

2007; Lin et al., 2008; Liang and Langston, 2009; Saygin and Kennet, 2012; Behr et al., 2013; Haned et al., 2015; Corela et al., 2017).

The uncertainty on the source locations of ASN can become demanding while interpreting results from seismic noise cross correlations (Behr et al., 2013). ASN mostly comprises surface waves, which are less attenuated and have sources close to the Earth's surface in the oceans. The weakest and the most energetic known ambient noise are the hum and the microseisms, respectively. The hum signals can be recorded in a period band from 30 to $300 \mathrm{~s}$. The generation mechanism is the same for the primary microseisms (PM) and the hum, but also considering gravity waves for the PM and infragravity waves for the hum (Ardhuin et al., 2015). In this article, we will focus on the microseisms that mainly consist of Rayleigh waves in the frequency band of $0.03-0.33 \mathrm{~Hz}$, and whose sources vary in time, frequency, and azimuth.

Microseism spectra display two peaks. The peak in the frequency band $0.03-0.1 \mathrm{~Hz}$ is called $\mathrm{PM}$, or singlefrequency microseism, whereas the peak that appears in the frequency range from 0.1 to $0.33 \mathrm{~Hz}$ is the secondary microseism (SM), or double-frequency microseism.

The PM is generated when the ocean waves break near the shore and interact with the sloping sea floor. The wave energy is directly converted into seismic waves through 
pressure fluctuations at the shallow ocean bottom. In contrast, the generation of the SM depends on the interaction of two ocean gravity waves of similar periods that are traveling in opposite directions. When these ocean waves meet, they produce standing gravity waves, which in their turn, cause a nonlinear pressure perturbation close to the ocean surface (Longuet-Higgins, 1950). Hasselmann (1963) extended this model to random ocean wavefields. This theory has been applied to quantitatively model surface waves (e.g., Kedar et al., 2008; Ardhuin et al., 2011; Stutzmann et al., 2012) and more recently to body waves (e.g., Obrebski et al., 2013; Gualtieri et al., 2014; Farra et al., 2016; Meschede et al., 2017).

The SM dominate seismic noise all over the world. Dorman et al. (1993) distinguished the SM according to their generation mechanism. It can be generated by swell from distant storms or caused by waves induced by local winds, resulting in the splitting of the SM peak into two peaks. One of these peaks is at about $0.1-0.2 \mathrm{~Hz}$, and the other is between 0.2 and $0.5 \mathrm{~Hz}$ (see fig. 18 in Stephen et al., 2003). Stephen et al. (2003) proposed that the first peak $(0.1-0.2 \mathrm{~Hz})$ is associated with swell from distant storms, and the second one $(0.2-0.5 \mathrm{~Hz})$ is due to local sources, such as local sea state and/or local wind. Bromirski et al. (2005) found similar results. Later, Ardhuin et al. (2011) proposed three classes that represented different situations that were capable of generating microseismic sources. Class I corresponds to the generation within a single storm when the ocean-wave directional spectra are broad. Class II characterizes the generation close to the coast when the incoming ocean waves meet the ones reflected on the shore. Finally, Class III classifies the generation caused by a swell meeting another swell or a wind sea.

There are a few studies that consider both PM and SM. Stehly et al. (2006) performed an investigation on seismic noise from its long-range correlation properties and concluded that PM and SM noise directions are different, which indicates that the two dominant peaks do not have the same region of origin. Also, their results showed that sources of SM remain stable in time, and the sources of PM exhibit strong variability. Later, Gerstoft and Tanimoto (2007) suggested not only that the locations of excitation are different, but also that they change with the season. They achieved this conclusion by analyzing the noise-source directions during winter months and summer months.

Through the following years, several research papers were published that demonstrated agreement with these conclusions (e.g., Schimmel et al., 2011; Moni et al., 2013; Sergeant et al., 2013). Besides the seasonal variability, seismic noise is also dependent on the station location within continents, close to the coast, or on islands (e.g., Stutzmann et al., 2009).

In this study, we used two different deployments; specifically, YW and CVPLUME in the Cape Verde Islands. The first is composed of seven seismic stations that were recording continuously for $2 \mathrm{yr}$, from August 2002 to September 2004. The second, with 38 stations, was con-

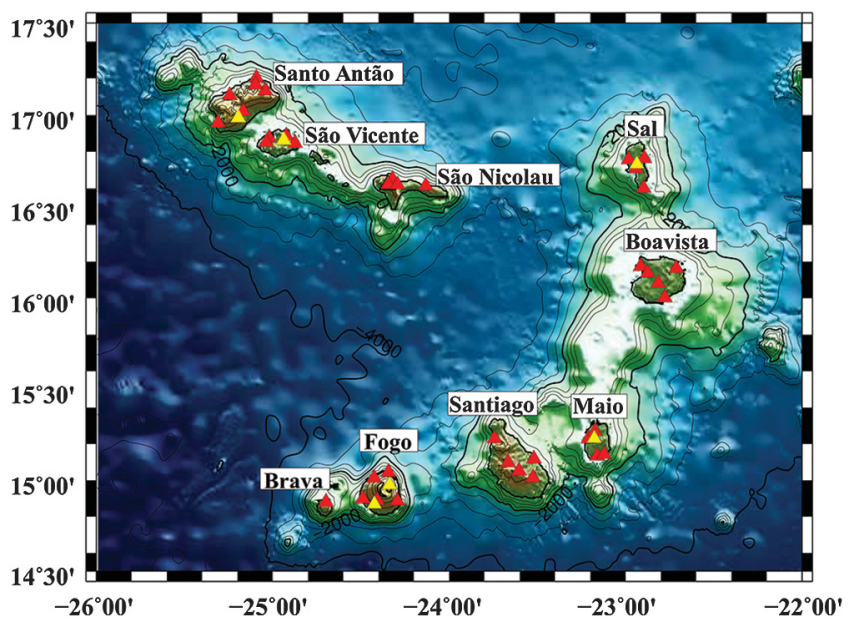

Figure 1. Geographic distribution of the islands and bathymetry of the archipelago (contour interval 2,000 m). Triangles in red and yellow represent the CVPLUME and YW seismic stations, respectively.

tinuously recording from December 2007 to September 2008. Using the data collected by these two networks, we performed the time-frequency-dependent polarization analysis (Schimmel and Gallart, 2004; Schimmel et al., 2011) to detect polarized signals in the time-frequency domain and to determine their back azimuth (BAZ). With this information, we were able to characterize the SM sources in Cape Verde and also to compare them with the locations of SM noise sources that were predicted by numerical wave modeling.

\section{The Cape Verde Archipelago}

The Cape Verde archipelago consists of nine inhabited volcanic islands, an uninhabited island, and several islets that are located in the eastern Atlantic Ocean, $500 \mathrm{~km}$ of Senegal, West Africa $\left[14^{\circ}-18^{\circ} \mathrm{N}\right.$ and $\left.22^{\circ}-26^{\circ} \mathrm{W}\right]$.

The islands are built on the top of the largest Atlantic within-plate bathymetric anomaly in ocean basins, the Cape Verde Rise. It has formed as the African plate moved slowly towards the east over a fixed mantle hotspot (Ali, 2002) via persistent volcanic activity; this has been occurring since the Oligocene (Torres et al., 2002) and continues to present times.

The archipelago has a particular west-facing horseshoe shape distribution with two diverging chains, with older islands in the east and younger islands in the northwest and southwest. Traditionally, two main groups are identified-a windward group (Santo Antão, São Vicente, São Nicolau, Sal, and Boavista) and a leeward group (Maio, Santiago, Fogo, and Brava) (Fig. 1).

However, the regional bathymetry suggests a different division, based on the coalescence of the submarine pedestal of the island edifices. Specifically, this would be two chains: a northern chain, comprising the islands of Santo Antão, 
São Vicente, Santa Luzia, and São Nicolau; and an east-tosouthern chain, comprising Sal, Boa Vista, Maio, Santiago, Fogo, and Brava. The bathymetry also revealed, in the vicinity of the islands, the presence of several volcanic edifices that never reached the sea level (Ramalho, 2011).

Despite the latitude, the climate in Cape Verde is tropical arid with temperatures generally not too high. This is mainly due to four important systems - the subtropical Azores and Santa Helena anticyclones, the low equatorial pressures, the Canary maritime current, and the thermal depression over the African continent during the summer. The dry season includes almost nine months (November to mid-July), and it is characterized by strong maritime winds. From mid-July to October, the archipelago is affected by the rainy season, caused mostly by the flow of tropical maritime air and the passage of the African east waves and isolated convective systems. Cape Verde is also affected by the West African monsoon, winds that blow southeast during the warmer months and northeast during the colder months (Cropper, 2013).

It is not common for significant storms or hurricanes to affect Cape Verde. However, the southern islands are close to the starting point of the hurricane's path. As soon as they form, they move toward the west or northwest and head to the Caribbean. Those that reach the southern islands are usually not strong, considering that at that time they are still in a tropical depression stage.

\section{Seismic Data and Preprocessing}

We processed three-component data records (northsouth, east-west, and vertical) that were obtained through two different temporary deployments: YW (Lodge and Hellfrich, 2010) and CVPLUME (Vinnik et al., 2012; see Fig. 1).

The YW network is composed of seven Güralp CMG$3 \mathrm{~T}$ broadband temporary stations, continuously recording for $2 \mathrm{yr}$, from 2002 to 2004, and sampling at $50 \mathrm{~Hz}$. Several gaps were detected in the stations of this network; even so, the results are in agreement with the ones computed using the CVPLUME network.

The CVPLUME network recorded continuously from December 2007 to September 2008. It is composed of 38 Earth Data BB(PR6-24) stations that were equipped with Güralp CMG-3ESP (60 s) sensors, installed over the nine inhabited islands, and sampled at $100 \mathrm{~Hz}$.

Data were preprocessed using Seismic Analysis Code. The horizontal components were rotated through north and east to correct seismic station installation orientation errors. The instrument response was removed to convert each record to ground velocity and then decimated to 1 sample per second, in order to extract frequency-dependent noise polarization from the continuous three-component records in the $0.03-0.33 \mathrm{~Hz}$ frequency range. For practical reasons in the following polarization analysis, the continuous daily records were cut into $2 \mathrm{hr}$ segments. Problematic data were removed through different consistency and quality checks during the processing. Earthquake signals were detected; however, at the microseismic frequency range, they last for shorter time spans than the microseisms. Through a bootstrap resample analysis, we downweighted the signals with BAZs that were clustered in time for short duration instead of being distributed over several hours. This step was performed automatically before the analysis of the polarization measurements.

\section{Polarization Analysis}

To analyze and characterize the primary and secondary microseismic signals, we performed a frequency-dependent polarization analysis of the recorded signals (Schimmel and Gallart, 2004; Schimmel et al., 2011) in the frequency range between 0.03 and $0.33 \mathrm{~Hz}$. The polarization described the particle ground motion at the receiver, taking into consideration the seismic records along the three directions (northsouth, east-west, and vertical). Polarization analysis was performed on individual stations, so no dense network was needed, as it would have been with the beamforming method. Nevertheless, in both cases, and because surface waves propagate parallel to the Earth's surface, the determination of the distance to the source was not possible. Only the propagation direction could be determined.

The polarization analysis enabled detection of signals that were elliptically polarized in the vertical plane. We determined two attributes of the polarized signal: the instantaneous degree of polarization (DOP) and the azimuth of the incoming waves (BAZ). Microseisms are mainly composed of Rayleigh waves, which have elliptical polarization. In the ideal situation, this ellipse stands in the vertical plane, which connects the sensor and the source. The azimuth toward the source-BAZ - is estimated at every station in the timefrequency domain. There is a $180^{\circ}$ ambiguity in the determination of BAZ, which is easily removed by assuming that the orientation of ground-motion ellipse is retrograde, as is usually the case for fundamental-mode Rayleigh waves recorded in stations installed in rocky ground (Tanimoto and Rivera, 2005).

The DOP is a quality measurement connected to the stability of an arbitrary polarization in time, based on the assumption that the polarization of a high-quality signal should not vary in a small time window (Schimmel and Gallart, 2003). The DOP is built from the semimajor and semiminor axes of the ellipse that best fits the ground motion, which are determined through the analysis of the eigenvalues matrix between the three components of the seismogram. A detailed description of the polarization analysis method can be found in Schimmel et al. (2011).

The DOP parameter is normalized and goes from 0 to 1 , where 0 means a random ground motion and 1 corresponds to a perfectly polarized signal of elliptical particle motion in a vertical plane. Our detections were based on a DOP larger than 0.7 , in order to keep only the measurements 


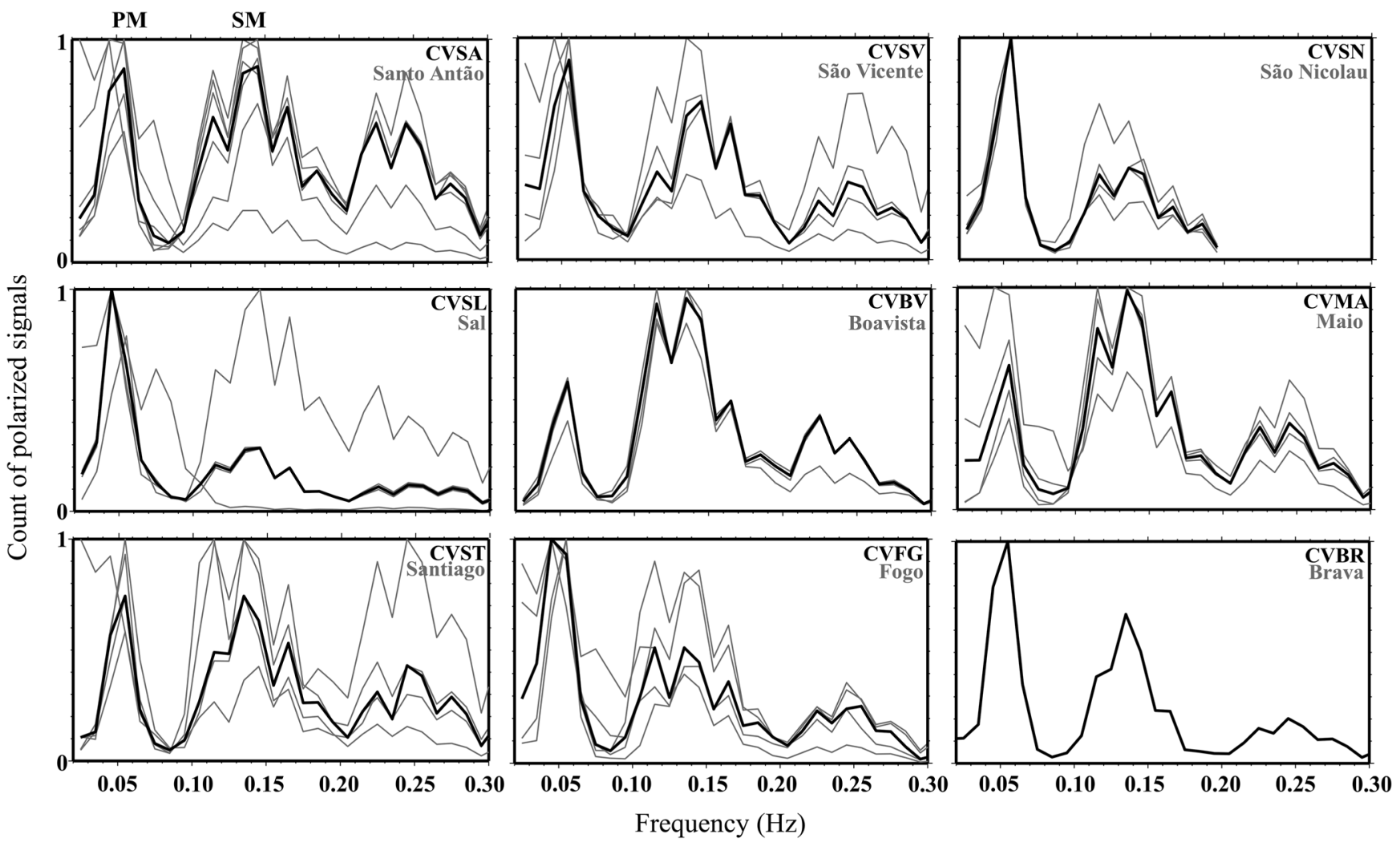

Figure 2. Polarization spectra for all CVPLUME stations. Gray lines represent the result for all stations on the same island. A black line represents the median of the observations. PM, primary microseism; SM, secondary microseism. The maximum value of the polarized signals was normalized to 1 .

corresponding to stable elliptical polarization within the frequency-dependent polarization analysis window.

The polarization analysis outcome is a matrix with time (s), frequency $(\mathrm{Hz}), \mathrm{DOP}$, and source BAZ $\left(^{\circ}\right)$ for all the signals detected at each seismic station. With these data, we analyze the microseismic sources originating inside the horseshoe chain and their variations with time and frequency.

\section{Results}

We started by quantifying the number of elliptically polarized signals as a function of frequency, for each station and for both seismic networks. Among the selected signals with DOP values larger than 0.7, most of them have DOP values between 0.75 and 0.85 . The polarization spectrum is defined as the normalized number of polarized signals as a function of frequency. It is shown in Figure 2 for all stations from CVPLUME network where individual stations in each island are plotted in gray. The black line represents the median. Results for the YW network are similar and can be seen in Figure A1. The polarization spectra are evidence of a bimodal distribution, with a minimum number of detected signals between the PM and SM, around $0.1 \mathrm{~Hz}$, for all stations. Within the SM frequency band, and for most of the stations, we recognized a bimodal distribution of second order, with a minimum around $0.20 \mathrm{~Hz}$. At the stations in
São Nicolau, we detected a systematic signal above $0.20 \mathrm{~Hz}$ coming from all BAZ directions. It is possible that this was caused by cultural noise, which we discarded (the top right part of Fig. 2).

The relative number of polarized signals between the SM and PM frequency band varies between the different stations (Fig. 2). CVSL stations (Sal Island) exhibit, in general, a higher number of polarized signals in the PM frequency band, and CVSN (São Nicolau Island) exhibits an equivalent amount of polarized signals in both PM and SM. For all the other stations, the number of polarized signals is larger in the SM frequency band.

The observed separation between the PM and the SM is also visible across the entire recording period. In Figure 3, we display the time-frequency-dependent polarization spectra for two stations, CVMA3 and MAIO, from CVPLUME and YW networks, respectively. Red colors correspond to the highest number of detected elliptically polarized signals. The number of signals has been normalized to 1 per day, and the color scale has been saturated to 0.5. Two continuous red bands mark the PM and low-frequency SM signals, which are present for both stations across the entire recording period. We observe no strong seasonal variations in these frequency bands. The same patterns are found for the other stations of the archipelago. The absence of seasonal variation can be related to the location of Cape Verde, close to the 


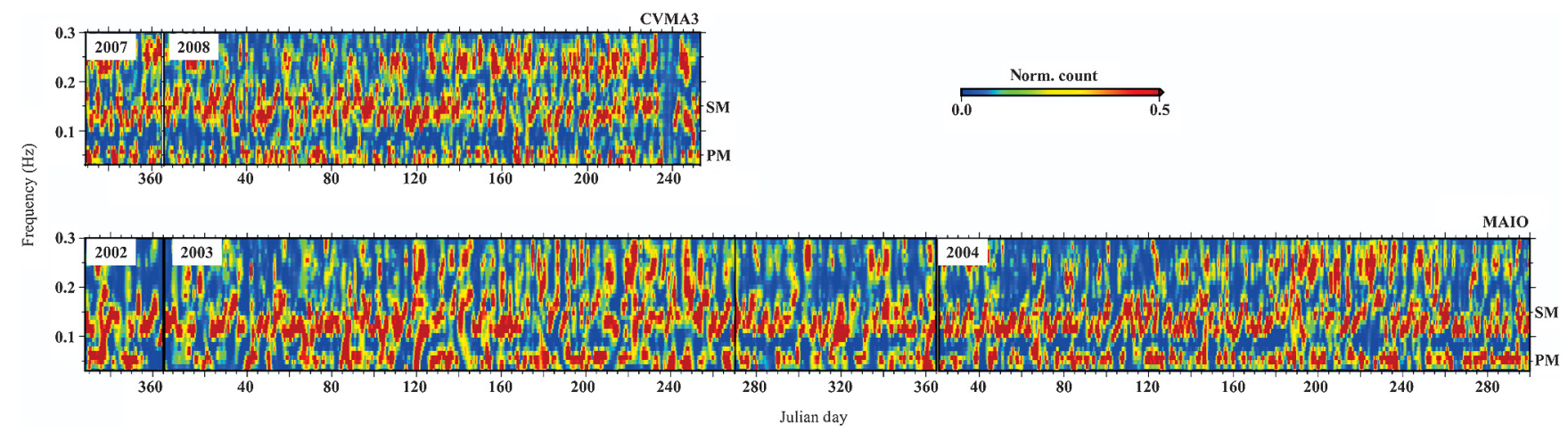

Figure 3. Polarization spectra as a function of time and frequency for stations CVMA3 and MAIO. Red colors correspond to the maximum number of polarized signals. PM and SM signals are present in both stations and visible as horizontal red bands.

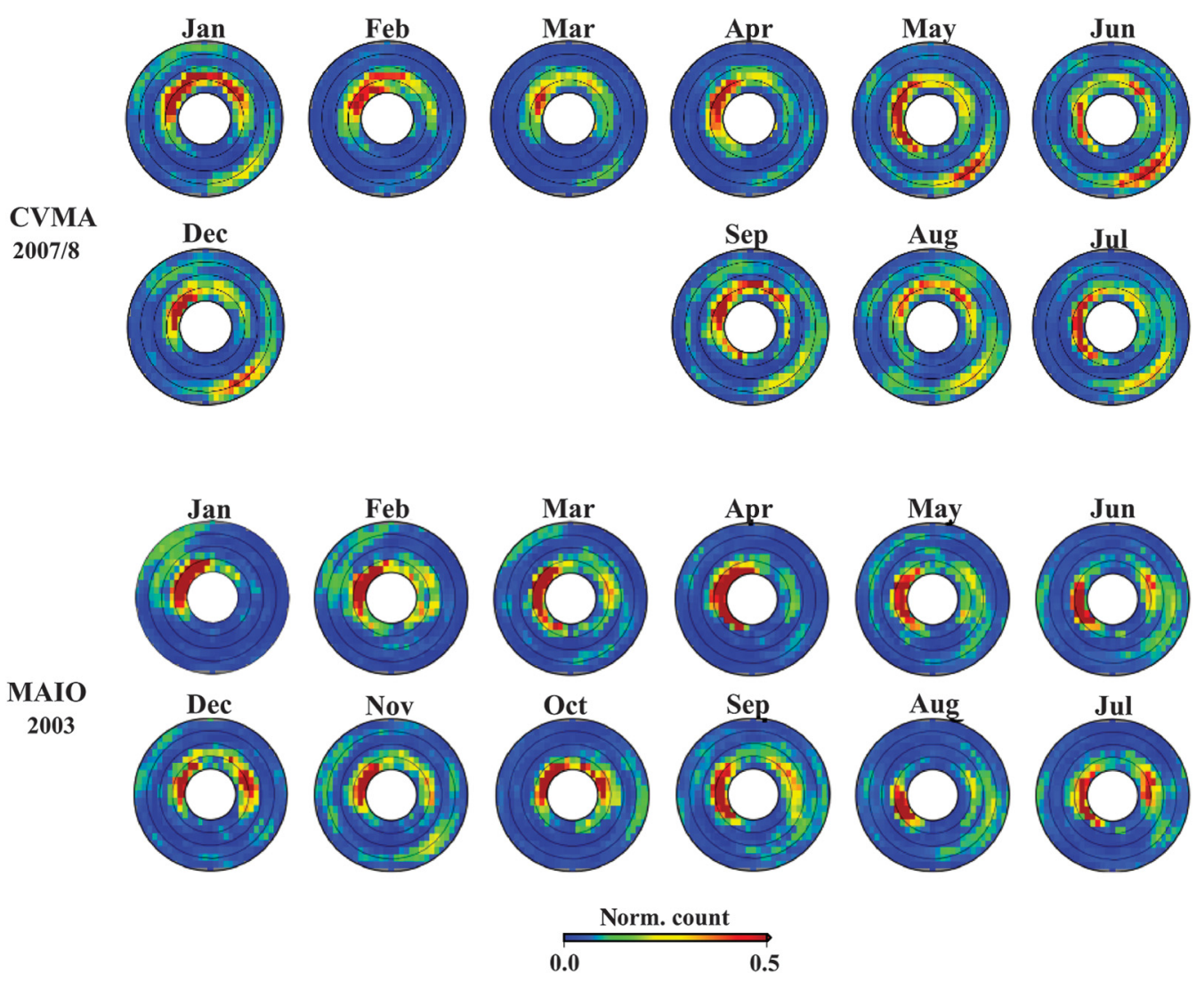

Figure 4. Monthly variations of back azimuth (BAZ) in 2003 at station MAIO and 2008 at station CVMA, both located on Maio Island. Red colors represent the maximum number of polarized signals, and each small circle corresponds to a particular frequency. The inner circle is at $0.1 \mathrm{~Hz}$, and the outer circle is at $0.33 \mathrm{~Hz}$, with small circles plotted at a $0.05 \mathrm{~Hz}$ interval.

Equator. At higher frequencies $(0.2-0.33 \mathrm{~Hz})$, more polarized signals are detected during the northern hemisphere spring and summer in both stations (CVMA3 and MAIO), and this feature repeats itself for different years (Fig. 3). A similar pattern was found for station TAM in Algeria (Schimmel et al., 2011), which is located at a similar latitude above the equator.

We represented the number of elliptically polarized signals as a function of BAZ at each seismic station. Figure 4 shows the monthly variations of the SM BAZ, as a function of frequency, for stations MAIO (YW) and CVMA (CVPLUME), both located on Maio Island. The station here defined as CVMA combines the four stations (CVMA1CVMA4) from CVPLUME deployment, which were located on this island.

Both results exhibit, at the very least, a dominant BAZ. Also, despite representing two different years, the patterns are very similar, presenting just small variations between 


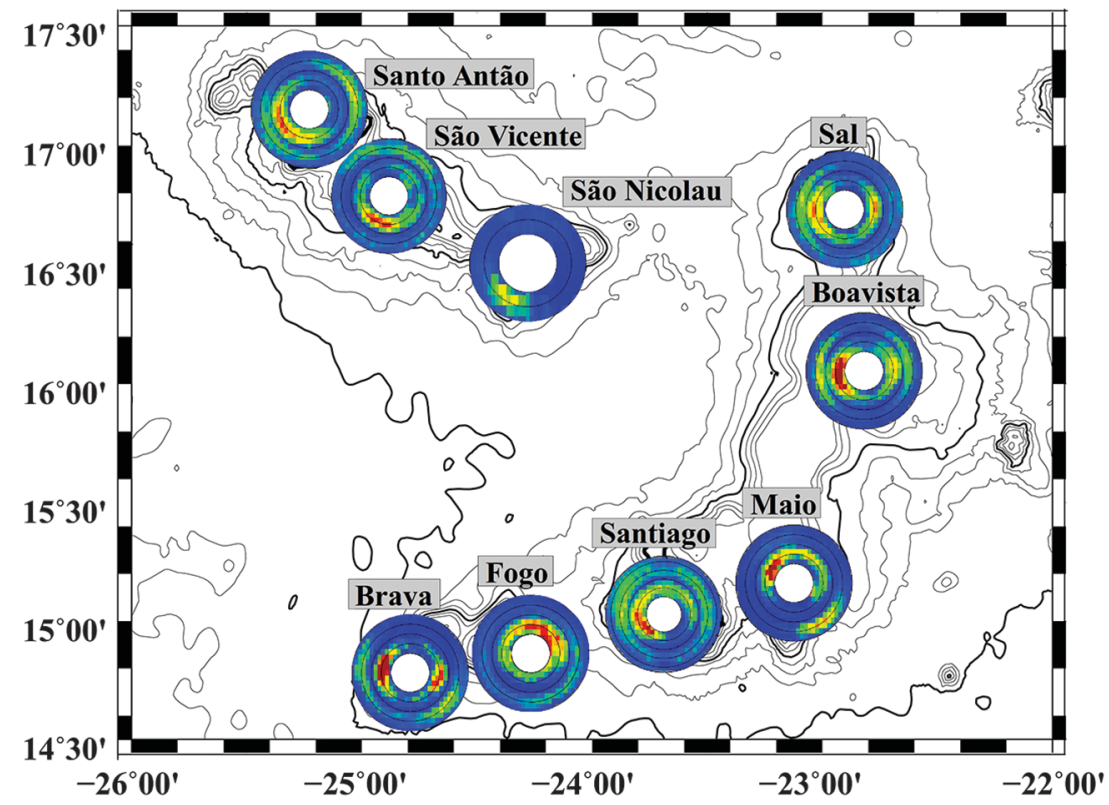

Figure 5. Detection of SM-polarized signals throughout the time for CVPLUME deployment. Diagrams represent an average of all the stations per island. The inner circle is at $0.1 \mathrm{~Hz}$, and the outer circle is at $0.33 \mathrm{~Hz}$, with small circles plotted at a $0.05 \mathrm{~Hz}$ interval.

0.1 and $0.2 \mathrm{~Hz}$. At higher frequencies (above $0.2 \mathrm{~Hz}$ ), we detected another dominant BAZ, which is also present in both results; however, it is stronger and more evident in CVMA stations. Station MAIO exhibits a clear source direction in the frequency band $0.1-0.2 \mathrm{~Hz}$, stable all year in the northwest-southwest direction. A second source, neither stable nor as strong as the previous one, is also present, pointing to a direction between northeast and southeast.

At CVMA stations, besides the similar source BAZ at lower frequencies (below $0.2 \mathrm{~Hz}$ ), there is also an important source, around $0.25 \mathrm{~Hz}$, that is present almost every month; this one has a clear direction toward the southeast. At this frequency, we are probably facing a local source toward the southeastern coast. It can be related to rain showers, stronger winds, or a sandstorm from Sahara Desert.

To better understand the distribution of the sources at Cape Verde, we present, in Figure 5, the detected polarized signals in the SM frequency band in each island. In São Nicolau, we only represent the frequency band between 0.1 and $0.2 \mathrm{~Hz}$, due to the detection of cultural noise at higher frequencies, which we already mentioned. As said before, stations from the same island present similar dominant BAZ distributions. Therefore, we plot the normalized sum of all SM-polarized signals, within each one of the islands, as a function of the BAZ. This representation favors the visualization of the results for the archipelago, and it gives a better idea of the dominant sources. Signals have been normalized to 1 , and the color scale has been saturated, so that bins above 0.5 are represented in dark red.

In each island, at least one clear and dominant source BAZ is observed for the SM-polarized signals. At each island, there is at least a clear BAZ in the frequency band $0.1-0.2 \mathrm{~Hz}$, in most cases pointing toward the middle of the horseshoe shape chain of islands. Stations from CVSL (Sal) and CVBV (Boavista) also record signals coming from the east.

At higher frequency, around $0.25 \mathrm{~Hz}$, CVMA stations (Maio Island) detected a clear BAZ toward the southeast. In CVSA stations (Santo Antão) and CVSV stations (São Vicente), we observed BAZ toward the northeast, which are in agreement with the direction of the local winds that have a larger effect on the islands of the northern group.

Similar results have been obtained with the YW network data (Fig. A2).

\section{Discussion}

For both networks, and at almost all stations, the polarization spectra enable us to identify the SM and PM clearly, but the relative number of polarized signals between PM and SM varies among the islands (see Fig. 2). Nevertheless, the PM is always clearly visible. PM are generated by the interaction between ocean waves and the coast (Hasselmann, 1963). In Cape Verde, on top of the interaction of ocean waves with the island coasts, the presence of submarine seamounts between some of the islands may favor the interaction of the ocean waves with the sloping seafloor.

In the following, we focus only on the SM in the 0.1$0.33 \mathrm{~Hz}$ signals and compare our polarization measurement with an SM noise-source model. SM sources are pressure fluctuations close to the ocean surface generated by the interaction of ocean waves. We use the pressure power spectral density (PSD) on a grid of $0.5^{\circ}$ in latitude and longitude from the Integrated Ocean Waves for Geophysical and Other Application (IOWAGA) numerical wave model (Ardhuin et al., 2011) to compare with our BAZ measurements. The IOWAGA model is based on WAVEWATCH III(R) code (Tolman, 1991, 2014), and forced by $6 \mathrm{hr}$ wind analysis from the European Centre for Medium-Range Weather Forecasting. The model takes into account all wave-wave interactions, including those generated at the coast between incident and reflected waves. Reflected waves are computed for a coastal reflection coefficient of $10 \%$. The frequencydependent pressure PSD model is then multiplied by the surface-wave source site effect (Longuet-Higgins, 1950; Kedar et al., 2008; Ardhuin et al., 2011; Stutzman et al., 2012) to obtain the SM source maps every $6 \mathrm{hr}$ for seismic frequencies between 0.3 and $0.1 \mathrm{~Hz}$. Longuet-Higgins (1950) demonstrated that the source site effect modulates the pressure source recorded by seismic stations. This effect should be taken into account for an investigation of the source locations 
(a)
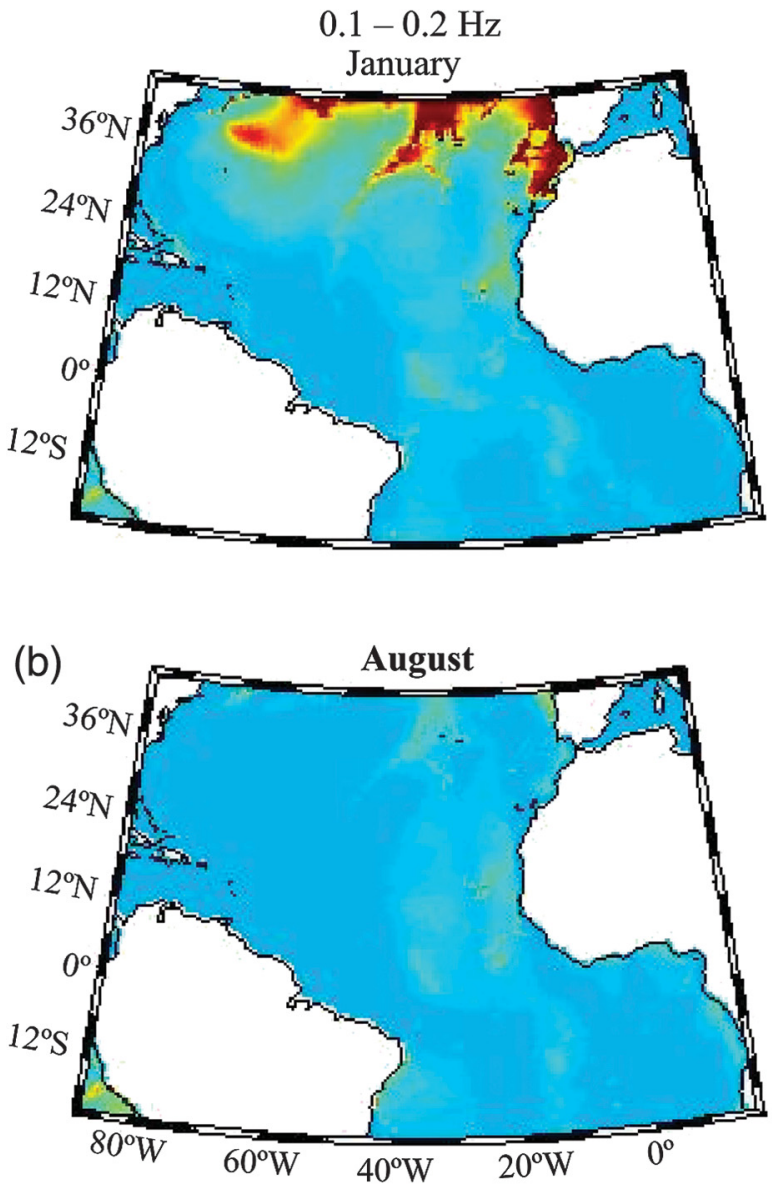

SM sources for:
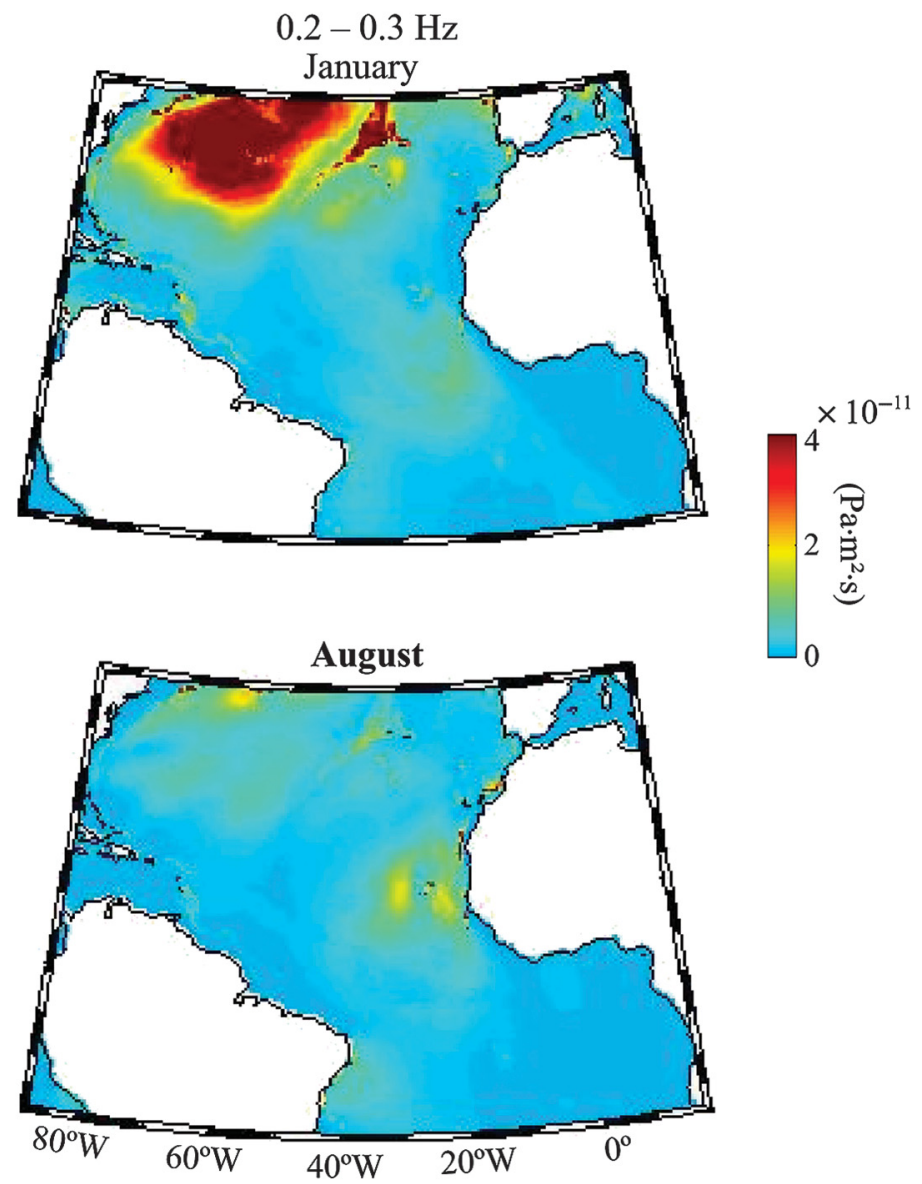

Figure 6. SM noise-source distribution maps averaged for (a) January and (b) August 2008 for the frequency bands $0.1-0.2 \mathrm{~Hz}(5-10 \mathrm{~s}$ ) and $0.2-0.33 \mathrm{~Hz}(3-5 \mathrm{~s})$, modeled with a $10 \%$ coefficient of ocean-wave coastal reflection.

that generate the detected signals to be possible (e.g., Kedar et al., 2008; Ardhuin et al., 2011; Stutzmann et al., 2012). Hereafter, we call SM sources the pressure sources combined with the source site effect.

Figure 6 shows the map of SM source distributions in two frequency bands $(0.2-0.33 \mathrm{~Hz}$ and $0.1-0.2 \mathrm{~Hz})$, averaged for January and August 2008. We observe that the SM sources with higher energy occur during the north hemisphere winter (Fig. 6a) in both frequency bands. The strongest sources are localized in the North Atlantic. Between 0.2 and $0.33 \mathrm{~Hz}$, sources spread across all the western North Atlantic basin, whereas at lower frequencies $(0.1-0.2 \mathrm{~Hz})$, strongest sources are located along the northern part of the Mid-Atlantic Ridge and at the west Iberia margin and Cadiz Gulf. The strong sources in the vicinity of the ridges are due to the source site effect, which amplifies sources at these locations with respect to elsewhere (e.g., Stutzmann et al., 2012; Gualtieri et al., 2014). No strong sources are observed close to Cape Verde. During the north hemisphere summer (Fig. 6b), SM sources are weaker. We observe some sources around Cape Verde in the $0.2-0.33 \mathrm{~Hz}$ frequency band. At lower frequencies, we observe no significant sources.
We observe strong large-scale seasonal variability of the SM source model in the $0.1-0.33 \mathrm{~Hz}$ frequency band (Fig. 6), but our polarization analysis shows no substantial seasonal variations of the detected signals in that frequency band (see Fig. 3). Furthermore, Figures 4 and 5 show that the measured BAZ are not toward the strongest North Atlantic sources; therefore, SM recorded in Cape Verde are probably generated by local sources. Cape Verde has a tropical oceanic climate, without an apparent change between summer and winter weather, as well as a quasi-persistent northeasterly wind that affects the archipelago. These characteristics of its climate may explain the absence of systematic seasonal variations in the low-frequency SM noise.

We present in Figure 7 the SM sources in the region around Cape Verde, averaged over the entire 2008 recording period. In Figure 7b, we show the measured BAZ averaged over the same recording period and all stations. In the lowfrequency band (inner circle), the BAZ points toward the southwestern sector, toward the aperture of the horseshoe formed by the distribution of the islands. The corresponding SM source model (Fig. 7a) does not show large sources along that BAZ. This BAZ points toward the direction of the tropical 

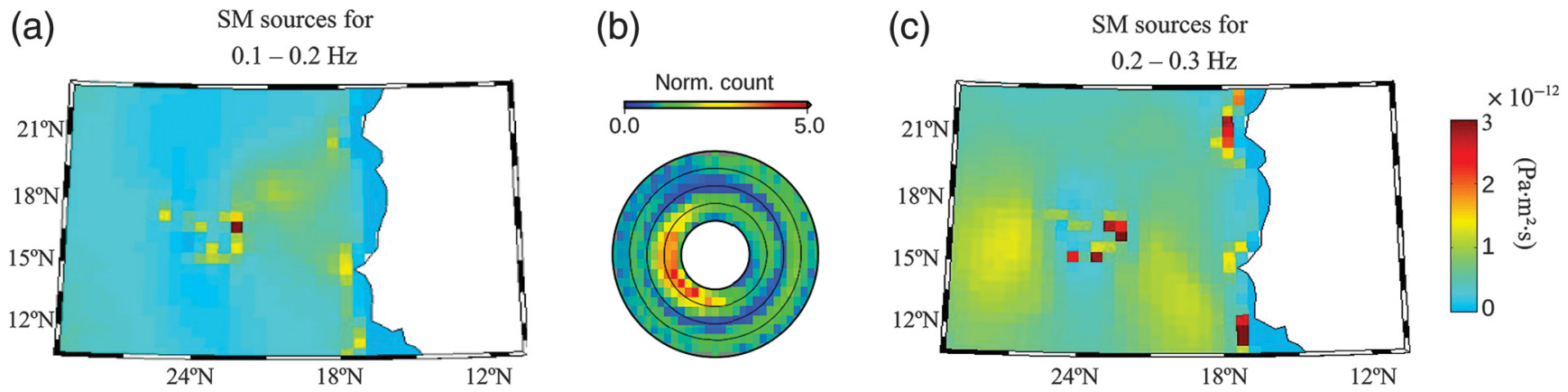

Figure 7. SM noise-source maps in the North Atlantic zoomed to Cape Verde area, averaged for the nine months of 2008, and computed in the frequency bands (a) $0.1-0.2 \mathrm{~Hz}$ and (c) $0.2-0.33 \mathrm{~Hz}$. (b) The BAZ was calculated by merging all the stations together. Inner and outer circles represent the frequencies of 0.1 and $0.33 \mathrm{~Hz}$, respectively.
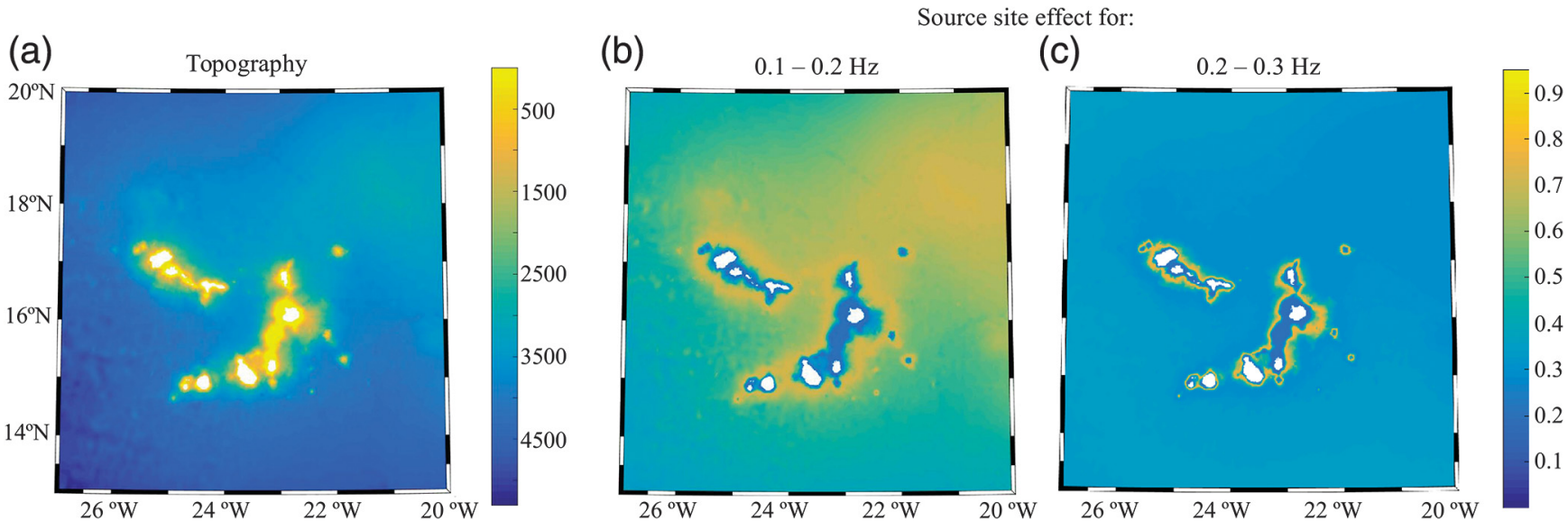

Figure 8. (a) Bathymetric map; (b,c) amplification factor for the seismic wave frequency of $0.1-0.2 \mathrm{~Hz}$ and $0.2-0.33 \mathrm{~Hz}$, respectively.

depressions that mark the starting point of the hurricane paths across the equatorial Atlantic. The SM source model also displays weaker but closer sources along the island coasts. The resolution of the model $(50 \times 50 \mathrm{~km})$ does not allow for distinguishing sources along coasts inside the island ring or along outside coasts. At higher frequencies (0.2-0.33 Hz), (Fig. 7c), the source model displays strong sources around the islands, close to the African coast, and weaker sources at the east and the west of the archipelago. These numerous sources probably explain the spread of the recorded BAZ.

We computed the site effect for sources close to Cape Verde (e.g., Stutzmann et al., 2012), using the digital bathymetric model (Weatherall et al., 2015). Figure 8 shows the General Bathymetric Chart of the Oceans (GEBCO) bathymetry model; it has a grid spacing of 30 arcsec, along with the source site effect in both frequency bands. For the frequency band $0.1-0.2 \mathrm{~Hz}$, any source located above an ocean layer 2500-3500 m thick will be strongly amplified. This corresponds to the area surrounding the archipelago and the area to the northeast. Very few BAZ are measured toward the northeast at these frequencies. The measured BAZ toward the east does not correspond to a local source that is strongly amplified by the source site effect. Our simple 1D model of the source site effect does not take into account the 3D crust variability of the archipelago. Between 0.2 and $0.33 \mathrm{~Hz}$, only SM sources located above 1500-2000 m ocean depths, which are close to the archipelago and at two areas along the African coast, can be strongly amplified. We observe that the most abundant BAZ points in the northeast to southeast direction.

\section{Conclusions}

We investigate, for the first time, the impact of the Cape Verde archipelago geometry and nearby bathymetry in the generation of seismic ambient noise in that area of the northeastern Atlantic ocean. The polarization spectra of the microseisms recorded by two different temporary networks allowed us to identify both PM and SM signals and showed that the relative number of polarized signals varies among the different islands.

Analysis of the number of polarized signals as a function of frequency revealed an SM that is divided into low- and high-frequency bands. The low-frequency SM is consistent throughout the year, and its BAZ does not show significant 
seasonal variations. On the contrary, the high-frequency SM seasonal variation displays a higher number of polarized signals in the northern hemisphere during the spring and summer.

We observed that in the SM frequency band, the dominant BAZ points toward sources within the horseshoeshaped archipelago or to nearby sources. A comparison with sources from the IOWAGA numerical ocean-wave model indicates that the most significant North Atlantic storms do not generate the recorded SM in Cape Verde.

Computation of the site effect in the archipelago reveals that local sources are amplified, thus suggesting that the horseshoe distribution of islands plays a key role in the microseismic noise generation in this region.

\section{Data and Resources}

Data from the 2002-2004 deployment (Cape Verde Mantle Structure) were obtained from Incorporated Research Institutions for Seismology (IRIS) Data Management Center at www.iris.edu, network code YW. Data from the 2007-2008 deployment (CVPLUME project) can be obtained from the GFZ Seismological Data Archive at geofon.gfz-potsdam.de/ waveform/archive/. All figures were made using Generic Mapping Tools (GMT; Wessel et al., 2013) available at http://gmt.soest.hawaii.edu. Standard data processing was handled with the Seismic Analysis Code (Goldstein and Snoke, 2005), which can be retrieved at ds.iris.edu/ds/ nodes/dmc/software/downloads/sac/. All websites were last accessed on November 2016.

\section{Acknowledgments}

The authors thank projects CVPLUME (Ref. PTDC/CTE-GIN/64330/ 2006) and Cape Verde Mantle Structure (YW network) for providing the broadband seismic data they used in this research. This study was partially supported by projects Atmosphere-Ocean-Solid Earth Coupling: Seismic Tools to Explore and Monitor the Oceans (STORM) (Ref. UTAP-EXPL/ EAC/0056/2017) and Transnational cooperation-Pessoa Program (PHCPESSOA) (Ref. 4318/40851YL). This is a contribution to project Fogo Island volcano: multi disciplinary Research on 2014 Eruption (FIRE) (Ref. PTDC/GEO- GEO/1123/2014). Fundação para a Ciência e Tecnologia (FCT) Ph.D. Grant Ref. PD/BD/114480/2016 supported Joana Carvalho. Publication supported by FCT - project UID/GEO/50019/2019-Instituto Dom Luiz. The authors are grateful to the European COST action TIDES (ES1401) for all the discussions and for supporting Short-term scientific mission (STSM) of the authors. The authors acknowledge Editor-in-Chief Thomas Pratt and reviewers for their help with the article.

\section{References}

Ali, M. Y. (2002). A geophysical study of lithospheric flexure in the vicinity of Cape Verde islands, Ph.D. Thesis, Worcester College and Department of Earth Sciences, University of Oxford.

Ardhuin, F., L. Gualtieri, and E. Stutzmann (2015). How ocean waves rock the Earth: Two mechanisms explain microseisms with periods 3 to 300 s, Geophys. Res. Lett. 42, no. 3, 765-772.

Ardhuin, F., E. Stutzmann, M. Schimmel, and A. Mangeney (2011). Ocean wave sources of seismic noise, J. Geophys. Res. 116, no. C9, doi: 10.1029/2011JC006952.
Behr, Y., J. Townend, M. Bowen, L. Carter, R. Gorman, L. Brooks, and S. Bannister (2013). Source directionality of ambient seismic noise inferred from three-component beamforming, J. Geophys. Res. 118, 240-248.

Bromirski, P. D., F. K. Duennebier, and R. A. Stephen (2005). Mid-ocean microseisms, Geochem. Geophys. Geosys. 6, no. 4, doi: 10.1029/ 2004GC000768.

Corela, C., G. Silveira, L. Matias, M. Schimmel, and W. H. Geissler (2017). Ambient seismic noise tomography of SW Iberia integrating seafloorand land-based data, Tectonophysics 700, 131-149.

Cropper, T. (2013). The weather and climate of Macaronesia: Past, present and future, Weather 68, no. 11, 300-307.

Dorman, L. M., A. E. Schreiner, L. D. Bibee, and J. A. Hildebrand (1993). Deep-water seafloor array observations of seismo-acoustic noise in the eastern Pacific and comparisons with wind and swell, in Natural Physical Sources of Underwater Sound, B. R. Kerman (Editor), Springer, Dordrecht, The Netherlands, 165-174.

Farra, V., E. Stutzmann, L. Gualtieri, M. Schimmel, and F. Ardhuin (2016). Ray-theoretical modeling of secondary microseism P waves, Geophys. J. Int. 206, no. 3, 1730-1739.

Gerstoft, P., and T. Tanimoto (2007). A year of microseisms in southern California, Geophys. Res. Lett. 34, no. 20, doi: 10.1029/ 2007 GL031091.

Goldstein, P., and A. Snoke (2005). SAC availability for the IRIS community, Incorporated Research Institutions for Seismology Newsletter, 7 (UCRL-JRNL-211140).

Gualtieri, L., E. Stutzmann, V. Farra, Y. Capdeville, M. Schimmel, F. Ardhuin, and A. Morelli (2014). Modelling the ocean site effect on seismic noise body waves, Geophys. J. Int. 197, no. 2, 1096-1106.

Haned, A., E. Stutzmann, M. Schimmel, S. Kiselev, A. Davaille, and A. Yelles-Chaouche (2015). Global tomography using seismic hum, Geophys. J. Int. 204, no. 2, 1222-1236.

Hasselmann, K. (1963). A statistical analysis of the generation of microseisms, Rev. Geophys. 1, no. 2, 177-210.

Kedar, S., M. Longuet-Higgins, F. Webb, N. Graham, R. Clayton, and C. Jones (2008). The origin of deep ocean microseisms in the North Atlantic Ocean, Proc. Math. Phys. Eng. Sci. 464, 777-793.

Koper, K. D., and V. L. Hawley (2010). Frequency dependent polarization analysis of ambient seismic noise recorded at broadband seismometer in central United States, Earthq. Sci. 23, 439-447.

Liang, C., and C. A. Langston (2009). Three-dimensional crustal structure of eastern North America extracted from ambient noise, J. Geophys. Res. 114, no. B03310, 1-14.

Lin, F. C., M. P. Moschetti, and M. H. Ritzwoller (2008). Surface wave tomography of western United States from ambient seismic noise: Rayleigh and Love wave phase velocity maps, Geophys. J. Int. 173, 281-289.

Lodge, A., and G. Hellfrich (2010). Depleted swell root beneath the Cape Verde Islands, Geology 34, no. 6, 449-452.

Longuet-Higgins, M. S. (1950). A theory on the origin of microseisms, Phil. Trans. Roy. Soc. Lond. A 243, 1-35.

Meschede, M., E. Stutzmann, V. Farra, M. Schimmel, and F. Ardhuin (2017). The effect of water column resonance on the spectra of secondary microseism $P$ waves, J. Geophys Res. 122, no. 10, $8121-8142$

Moni, A., D. Craig, and C. J. Bean (2013). Separation and location of microseism sources, Geophys. Res. Lett. 40, no. 12, 3118-3122.

Obrebski, M., F. Ardhuin, E. Stutzmann, and M. Schimmel (2013). Detection of microseismic compressional $(P)$ body waves aided by numerical modeling of oceanic noise sources, J. Geophys. Res. 118, no. 8, 4312-4324.

Ramalho, R. A. (2011). Building the Cape Verde Islands, Ph.D. Thesis, University of Bristol, Bristol, United Kingdom.

Saygin, E., and B. L. N. Kennet (2012). Crustal structure of Australia from ambient seismic noise tomography, J. Geophys. Res. 117, no. B01304, doi: 10.1029/2011JB008403. 
Schimmel, M., and J. Gallart (2003). The use of instantaneous polarization attributes for seismic signal detection and image enhancement, Geophys. J. Int. 155, no. 2, 653-668.

Schimmel, M., and J. Gallart (2004). Degree of polarization filter for frequency-dependent signal enhancement through noise suppression, Bull. Seismol. Soc. Am. 94, no. 3, 1016-1035.

Schimmel, M., E. Stutzmann, F. Ardhuin, and J. Gallart (2011). Polarized Earth's ambient microseismic noise, Geochem. Geophys. Geosys. 12, no. 7, doi: 10.1029/2011GC003661.

Sergeant, A., E. Stutzmann, A. Maggi, M. Schimmel, F. Ardhuin, and M. Obrebski (2013). Frequency-dependent noise sources in the North Atlantic Ocean, Geochem. Geophys. Geosys. 14, no. 12, 5341-5353.

Shapiro, N. M., and M. Campillo (2004). Emergence of broadband Rayleigh waves from correlations of the ambient seismic noise, Geophys. Res. Lett. 31, 1-4.

Shapiro, N. M., M. Campillo, L. Stehly, and M. H. Ritzwoller (2005). Highresolution surface-wave tomography from ambient seismic noise, Science 307, 1615-1618.

Stehly, L., M. Campillo, and N. M. Shapiro (2006). A study of the seismic noise from its long-range correlation properties, J. Geophys. Res. 111, no. B10, doi: 10.1029/2005JB004237.

Stephen, R. A., F. N. Spiess, J. A. Collins, J. A. Hildebrand, J. A. Orcutt, K. R. Peal, F. L. Vernon, and F. B. Wooding (2003). Ocean seismic network pilot experiment, Geochem. Geophys. Geosys. 4, no. 10, doi: 10.1029/2002GC000485.

Stutzmann, E., F. Ardhuin, M. Schimmel, A. Mangeney, and G. Patau (2012). Modelling long-term seismic noise in various environments, Geophys. J. Int. 191, no. 2, 707-722.

Stutzmann, E., J.-P. Montagner, A. Sebai, W. C. Crawford, J.-L. Thirot, P. Tarits, D. Stakes, B. Romanowicz, J.-F. Karczewski, J.-C. Koenig, et al. (2001). MOISE: A prototype multiparameter ocean-bottom station, Bull. Seismol. Soc. Am. 91, no. 4, 885-892.

Stutzmann, E., G. Roult, and L. Astiz (2000). Geoscope station noise level, Bull. Seismol. Soc. Am. 90, no. 3, 690-701.

Stutzmann, E., M. Schimmel, G. Patau, and A. Maggi (2009). Global climate imprint on seismic noise, Geochem. Geophys. Geosys. 10, no. 11, doi: 10.1029/2009GC002619.

Takagi, R., K. Nishida, T. Maeda, and K. Obara (2018). Ambient seismic noise wavefield in Japan characterized by polarization analysis of Hi-net records, Geophys. J. Int. 215, no. 3, 1682-1699.
Tanimoto, T., and L. Rivera (2005). Prograde Rayleigh wave particle motion, Geophys. J. Int. 162, no. 2, 399-405.

Tolman, H. L. (1991). A third-generation model for wind waves on slowly varying, unsteady, and inhomogeneous depths and currents, J. Phys. Oceanogr. 21, no. 6, 782-797.

Tolman, H. L. (2014). User manual and system documentation of WAVEWATCH III (R) version 4.07, Tech. Rept. NOAA/NWS/ NCEP/MMAB Tech. Note 222.

Torres, P. C., L. C. Silva, A. Serralheiro, C. Tassinari, and J. Munhá (2002). Enquadramento geocronológico pelo método k/ar das principais sequências vulcano-estratigráficas da ilha do sal - cabo verde, Garcia de Orta 18, nos. 1/2, 9-13 (in Portuguese).

Vinnik, L., G. Silveira, S. Kiselev, V. Farra, M. Weber, and E. Stutzmann (2012). Cape Verde hotspot from the upper crust to the top of the lower mantle, Earth Planet. Sci. Lett. 319/320, 259-268.

Weatherall, P., K. Marks, M. Jakobsson, T. Schmitt, S. Tani, J. E. Arndt, M. Rovere, D. Chayes, V. Ferrini, and R. Wigley (2015). A new digital bathymetric model of the world's oceans, Earth Space Sci. 2, no. 8, 331-345.

Wessel, P., W. H. Smith, R. Scharroo, J. Luis, and F. Wobbe (2013). Generic Mapping Tools: Improved version released, Eos Trans. AGU 94, no. $45,409-410$.

Yang, Y., M. H. Ritzwoller, A. L. Levshin, and N. M. Shapiro (2007). Ambient noise Rayleigh wave tomography across Europe, Geophys. J. Int. 168, no. 1, 259-274.

\section{Appendix}

The figures in this section show the similarity in the results obtained with both seismic networks-CVPLUME and YW. In Figure A1, the same bimodal distribution is present, between primary microseism (PM) and secondary microseism (SM). Figure A2 evinces the dominant back azimuth calculated with the YW stations, which is consistent with the CVPLUME results.

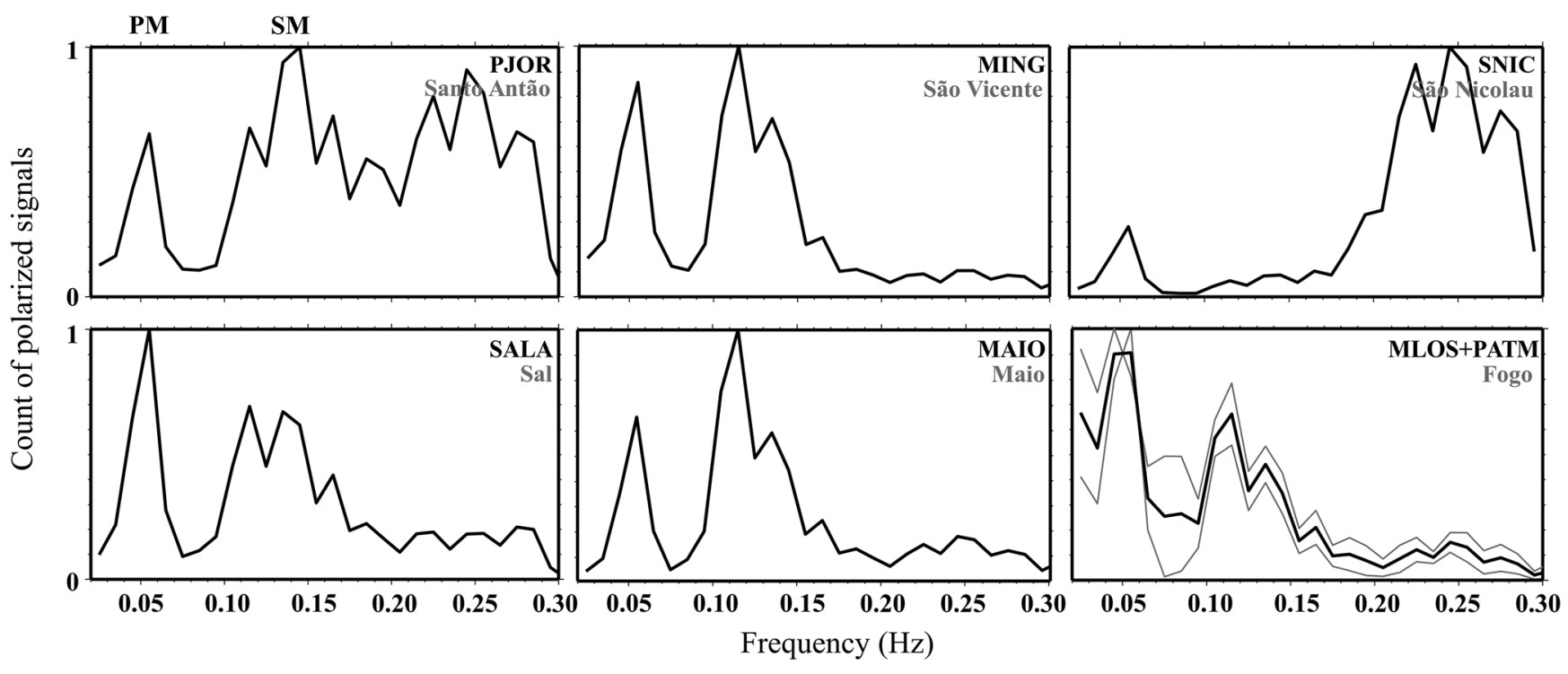

Figure A1. Polarization spectra for the YW stations. Gray lines represent the result for each station. Fogo is the only island with two stations; for that reason, it is the only one with the median of the observations (black line). PM, primary microseism; SM, secondary microseism. The maximum value of the polarized signals was normalized to 1 . 


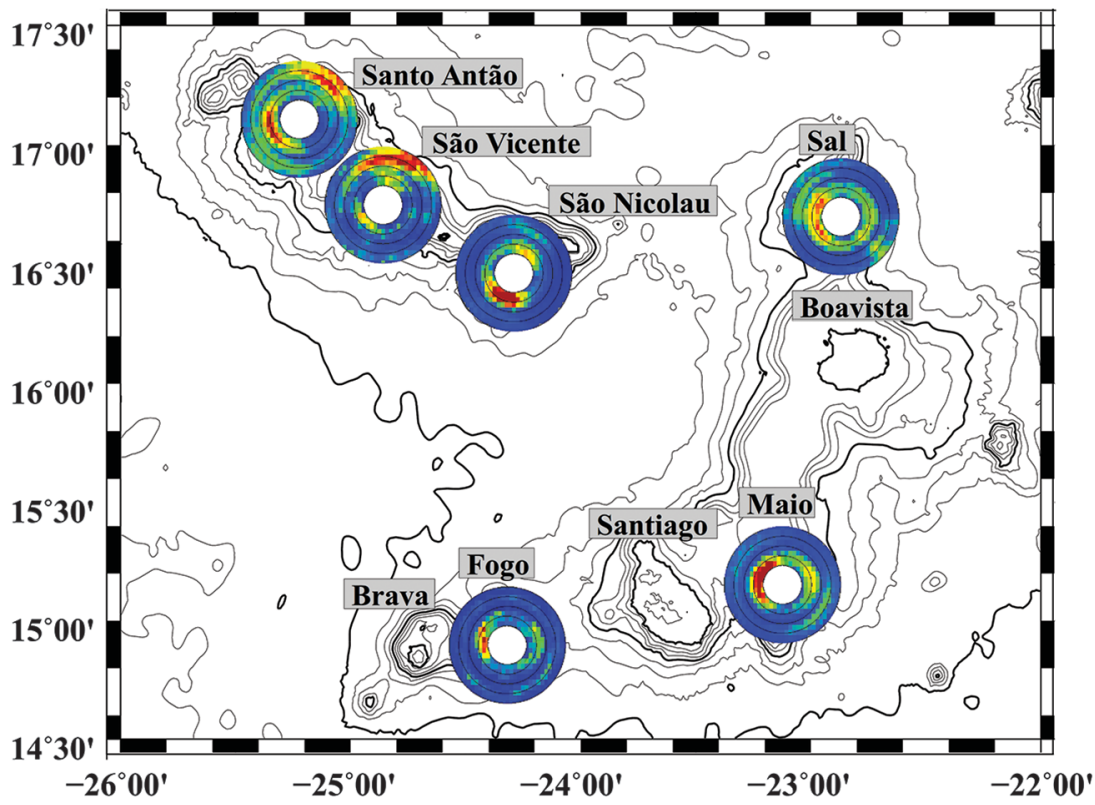

Figure A2. Detection of SM-polarized signals throughout the time for YW deployment. Diagrams represent an average of each station per island. In Fogo, the two stations are averaged together.

\author{
Joana F. Carvalho \\ Graça Silveira \\ Instituto Dom Luiz \\ Edificio C8, FCUL, Campo Grande \\ 1749-016 Lisbon, Portugal \\ jfcarvalho@fc.ul.pt \\ mdsilveira@fc.ul.pt
}

\section{Martin Schimmel}

Institute of Earth Sciences Jaume Almera

C/ Lluis Solé Sabaris $s / n$

E-08028 Barcelona, Spain

schimmel@ictja.csic.es

Eleonore Stutzmann

Seismology Group (Office 302)

Institut de Physique du Globe de Paris

1 rue Jussieu

75252 Paris, Cedex 5, France

stutz@ipgp.fr

Manuscript received 28 October 2018; Published Online 7 May 2019 